\title{
Pengembangan Aplikasi Evaluasi Dosen Berbasis Android dengan Keamanan Json Web token (JWT)
}

\author{
Eko Junirianto \\ eko.ilkom@gmail.com
}

\author{
Program Studi Teknologi Rekayasa Perangkat Lunak, Politeknik Pertanian Negeri Samarinda
}

\begin{abstract}
The development of this application is motivated by employee performance appraisal which is a general activity to be carried out as an evaluation material for employee performance and performance with the aim of improving employee quality, in this case, is to improve the performance of lecturers in higher education. The lack of effectiveness and efficiency in conducting lecturer evaluation activities that can only be done through the web is what underlies the design of android-based lecturer evaluation applications. The process of making an android application is on the security side of its web service data. To improve security in the android environment and web service will use the JSON Web token (JWT) method which is useful for exchanging data by using tokens. As well as the results of the design of an Android-based lecturer evaluation application with security Json Web token (JWT) is an android application that provides efficiency and effectiveness for students in conducting the evaluation process of lecturers. From the results of testing that has been done, it proves that starting from displaying the login page to exiting the application of lecturer evaluation can be done well with a successful status. And in the results of implementation and application testing, it can be concluded that the web service development can be used to integrate the Android-based lecturer evaluation application system with an existing system and with JWT security on the web service to help secure data exchange processes.
\end{abstract}

Intisari-Pengembangan aplikasi ini dilatarbelakangi oleh penilaian kinerja pegawai yang merupakan kegiatan umum untuk dilakukan sebagai bahan evaluasi terhadap performa dan kinerja pegawai dengan tujuan peningkatan mutu pegawai dalam hal ini adalah peningkatan kinerja dosen di pendidikan tinggi. Kurangnya efektifitas dan efisiensi dalam melakukan kegiatan evaluasi dosen yang hanya dapat dilakukan melalui web inilah yang mendasari dilakukannya perancangan aplikasi evaluasi dosen berbasis android. Proses dalam pembuatan aplikasi android adalah pada sisi keamanan data web servicenya. Untuk meningkatkan keamanan dalam lingkungan android dan web service akan memanfaatkan metode JSON Web token (JWT) yang berguna untuk melakukan pertukaran data dengan memanfaatkan token. Serta dari hasil perancangan aplikasi evaluasi dosen berbasis android dengan keamanan Json Web token (JWT) ini adalah aplikasi android yang memberikan efisiensi dan efektifitas bagi mahasiswa dalam melakukan proses evaluasi terhadap dosen. Dari hasil pengujian yang telah dilakukan, membuktikan bahwa mulai dari menampilkan halaman login sampai dengan keluar aplikasi evaluasi dosen dapat dilakukan dengan baik dengan status berhasil. Serta dalam hasil implementasi dan pengujian aplikasi maka dapat diambil kesimpulan pengembangan web service dapat dipergunakan untuk mengintegrasikan sistem aplikasi evaluasi dosen berbasis android dengan sistem yang sudah ada dan dengan keamanan JWT pada web service membantu proses pertukaran data lebih terjamin keamanannya.

Kata Kunci-Evaluasi kinerja pegawai; android; json web token; web service; evaluasi dosen

\section{PENDAhULUAN}

Dalam kegiatan organisasi, kegiatan penilaian kinerja pegawai adalah kegiatan umum yang dikerjakan [1][2] . Demikian pula dalam perguruan tinggi, baik yang berbentuk universitas, politeknik, akademi, maupun sekolah tinggi. Secara general, mengukur kinerja [3] adalah proses dimana suatu perguruan tinggi mengevaluasi performa atau kinerja dengan tujuan untuk peningkatan mutu pegawai [4] khususnya dosen di tingkat perguruan tinggi [5]. Proses evaluasi dosen adalah cara untuk mengetahui sejauh mana efektifitas dan efisiensi dosen dalam kegiatan belajar mengajar [6] . Proses penilaian meliputi, ciri-ciri kepribadian, persiapan mengajar, materi pembelajaran, penyampaian materi, dan evaluasi pembelajaran [7].

Kegiatan ini dilakukan untuk mengukur kinerja dosen dengan mengumpulkan informasi bagaimana para dosen dalam melakukan kegiatan belajar mengajar [8] dan membuat penilaian mengenai tindakan apa yang harus dilakukan agar peningkatan kualitas dosen dapat tercapai [9] [10]. Serta dalam meningkatkan sebuah kualitas dosen terdapat istilah kinerja yang sering disebut oleh para manajer, direktur, atau pimpinan yang menyatakan kondisi organisasi atau ruang lingkup yang dikelolanya [11], [12]. Dalam hal ini dapat dikatakan bahwa dalam evaluasi kinerja dosen memiliki kualitas dan kuantitas[13] yang dicapai oleh seseorang dalam melaksanakan tugas sesuai dengan tanggung jawabnya [14][15].

Politeknik Pertanian Negeri Samarinda merupakan salah satu organisasi pendidikan tinggi di Kota Samarinda dengan jumlah tenaga dosen pengajar sebanyak 93 orang dari total 8 program studi. Pada saat ini program studi Teknologi Rekayasa Perangkat Lunak Politeknik Pertanian Negeri Samarinda adalah program studi yang mengharuskan mahasiswa Manajemen Informatika melakukan evaluasi terhadap dosen jika ingin melihat kartu hasil studi melalui kuisioner yang berbasis web. Pengembangan aplikasi yang berbasis android diharapkan dapat memberikan efektifitas dan efisiensi kemudahan bagi mahasiswa dan dosen dalam mengisi maupun mendapatkan informasi evaluasi dosen. 


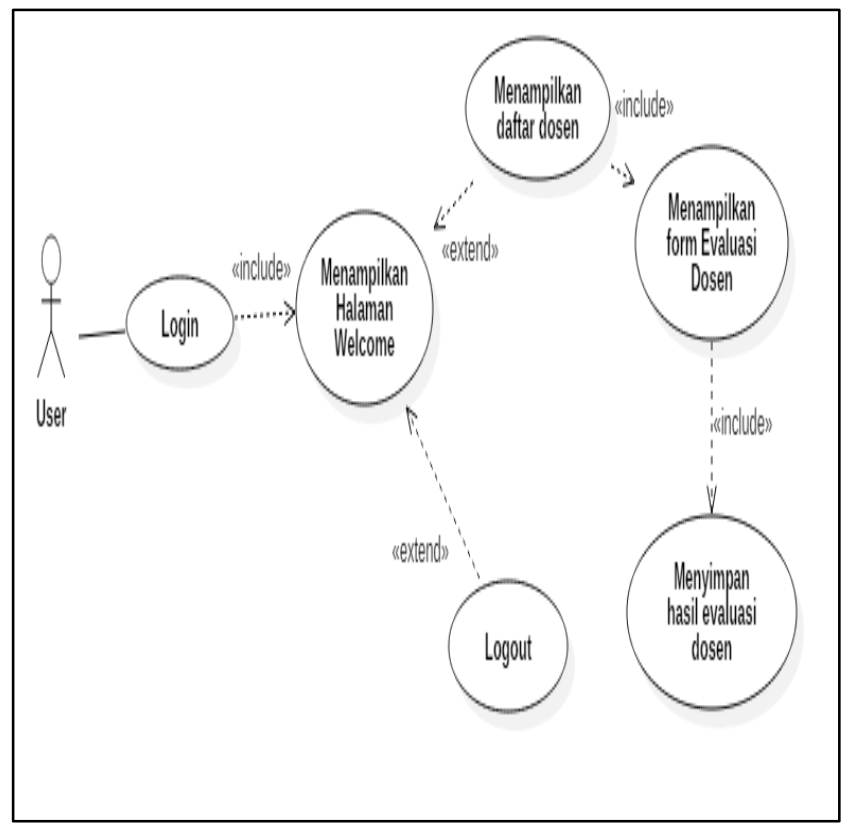

Gambar 1. Use case Sistem Evaluasi Dosen

Salah satu tantangan dalam pembuatan aplikasi android adalah pada sisi keamanan data web servicenya. Untuk meningkatkan keamanan dalam lingkungan android dan web service akan memanfaatkan metode JSON Web token (JWT) yang berguna untuk melakukan pertukaran data dengan memanfaatkan token.

\section{METODE PENELITIAN}

\section{A. Analisis}

Tahap analisis sistem adalah tahapan yang dilakukan sebelum tahap perencanaan sistem aplikasi. Analisis sistem (system analysis) adalah menerjemahkan dari bisnis proses suatu aplikasi yang utuh kedalam bagian-bagian sederhana dengan maksud untuk mengidentifikasikan dan mengevaluasi permasalahan, kesempatan serta hambatan yang terjadi dan kebutuhan yang diharapkan sehingga dapat diusulkan perbaikannya. Analisis yang akan dilakukan terhadap perancangan sistem ini ada dua yaitu analisis kelayakan dan analisis kebutuhan sistema aplikasi.

Analisis kelayakan sistem ini di diperuntukkan untuk menentukan apakah pengembangan sistema informasi ini dapat diteruskan atau tidak. Ini dilakukan agar sistem informasi tersebut dapat benar-benar bermanfaat sesuai kebutuhan. Analisis kebutuhan sistem aplikasi diperuntukkan untuk menentukan kebutuhan secara lengkap, maka analisis membagi kebutuhan sistem menjadi dua jenis yaitu analisis kebutuhan secara fungsional dan analisis kebutuhan secara non fungsional.

\section{B. Perancangan Sistem}

Setelah tahap analisis dilakukan, sehingga mendapatkan gambaran dengan jelas apa yang harus dikerjakan. Tahap

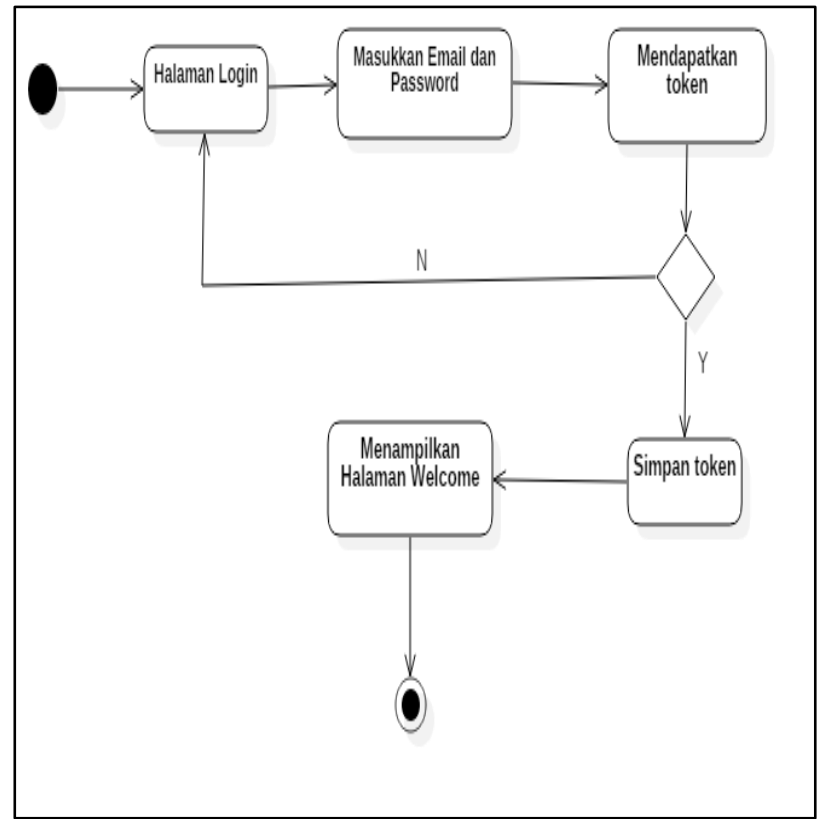

Gambar 2. Activity Diagram Login

berikutnya yaitu membuat perancangan sistem aplikasi dengan menggunakan UML. Dari UML ini diharapkan dapat menggambarkan sistem yang akan dibangun secara jelas. Pada perancangan sistem ini menggunakan use case diagram dan activity diagram. Berikut gambaran hasil rancangan sistem dengan UML.

Penjelasan dari Error! Reference source not found. yang menunjukan use case diagram adalah sebagai berikut :

1. Login, merupakan proses login untuk mengetahui identifikasi user.

2. Menampilkan halaman welcome, masuk untuk menampilkan data dosen dan memulai proses evaluasi dosen.

3. Menampilkan daftar dosen adalah proses menampilkan daftar para dosen pengampu yang akan dievaluasi.

4. Menampilkan form evaluasi dosen adalah proses menampilkan form pertanyaan evaluasi dosen.

5. Menyimpan hasil evaluasi dosen adalah proses mengumpulkan hasil evaluasi dosen.

6. Logout adalah proses keluar dari aplikasi evaluasi dosen

Activity diagram login ini merupakan rancangan proses login pada aplikasi Evaluasi Dosen. Pertama kali user menjalankan aplikasi, setelah itu aplikasi akan menampilkan halaman login. Kemudian user memasukkan email dan password jika proses berhasil maka aplikasi akan menampilkan halaman welcome untuk memulai evaluasi dosen, namun jika gagal maka aplikasi akan meminta ulang email dan password yang sesuai. Untuk activity diagram login dapat dilihat pada Gambar 2Gambar 3. 


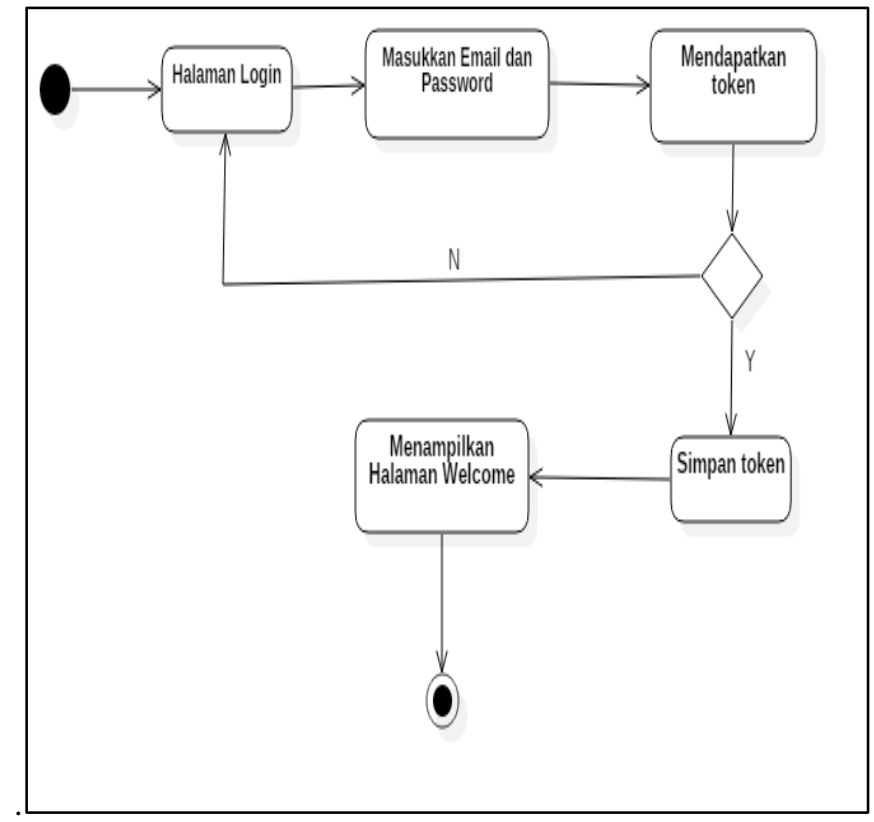

Gambar 3. Activity Diagram Login

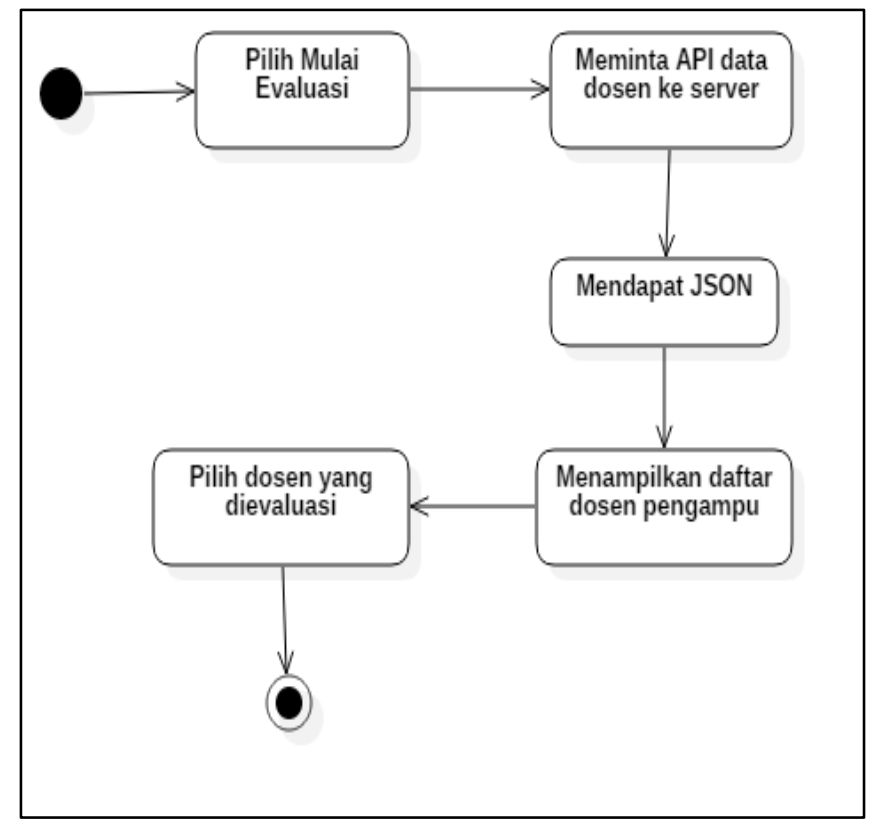

Gambar 4. Activity Diagram menampilkan dosen

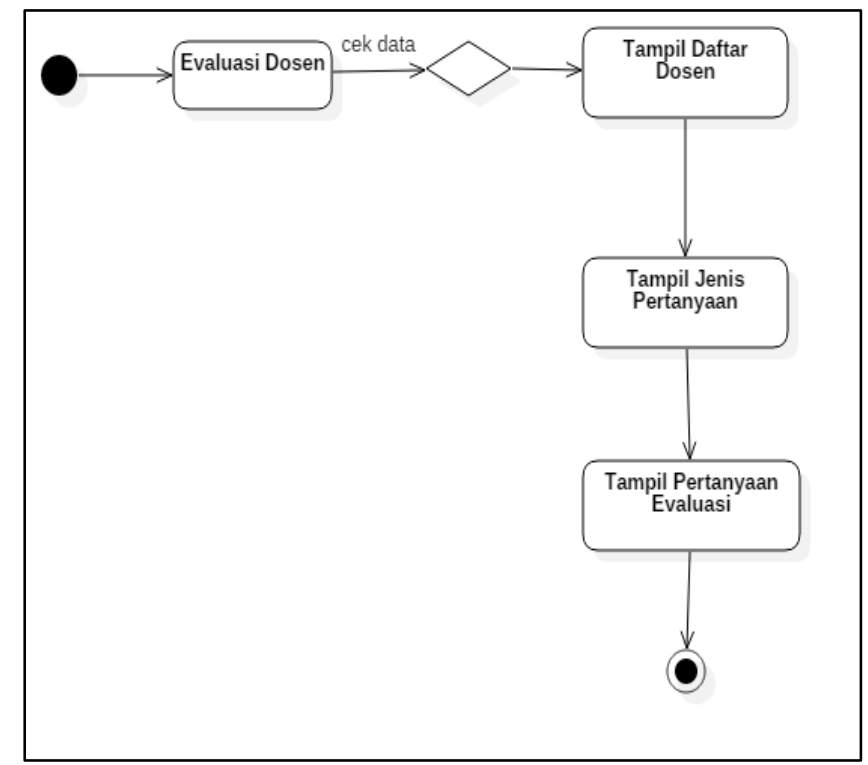

Gambar 5. Activity diagram form pertanyaan evaluasi dosen

Setelah melakukan proses login, maka aplikasi akan menampilkan halaman welcome untuk memulai proses evaluasi dosen, ketika user memilih untuk memulai evaluasi maka aplikasi akan menampilkan daftar dosen pengampu mata kuliah yang akan dievaluasi. Activity diagram untuk proses menampilkan daftar dosen pengampu mata kuliah dapat dilihat pada Gambar 3.

Activity diagram form pertanyaan evaluasi dosen, menggambarkan proses aplikasi menampilkan form pertanyaan kuisoner evaluasi dosen. Pertama mulai proses evaluasi kemudian sistem akan menampilkan daftar dosen pengampu, jika pilih salah satu nama dosen maka akan ditampilkan jenis pertanyaan yang berisi pertanyaanpertanyaan evaluasi dosen. Gambar activity diagramnya dapat dilihat pada Gambar 4.

Activity diagram menyimpan hasil evaluasi dosen ini menjelaskan tentang alur kuisioner evaluasi dosen telah selesai diisi dan disimpan ke database. Gambarnya bias dilihat pada Gambar 5. Activity diagram logout aplikasi evaluasi dosen menggambarkan proses keluar dari aplikasi evaluasi dosen Gambar 6. 


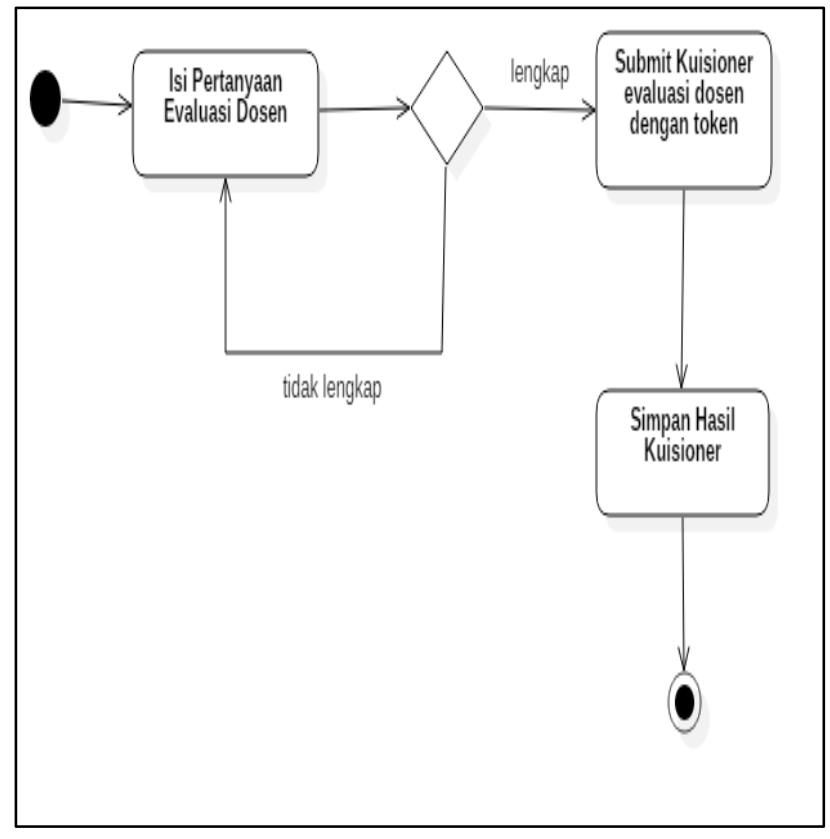

Gambar 6. Activity diagram menyimpan hasil evaluasi dosen

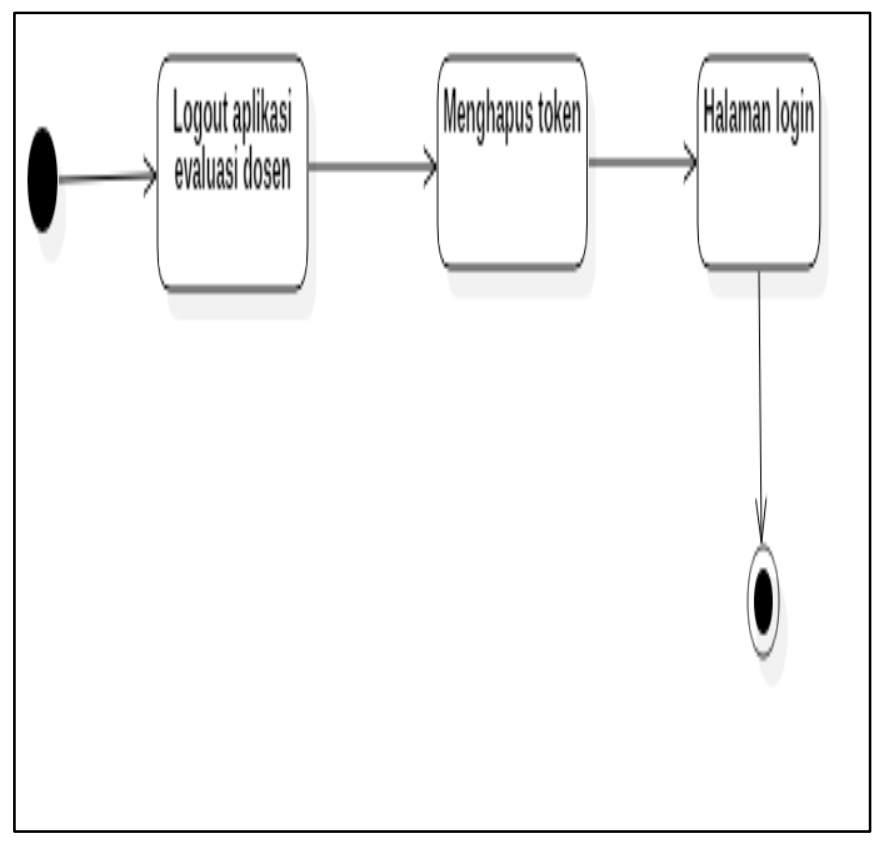

Gambar 7. Activity diagram logout

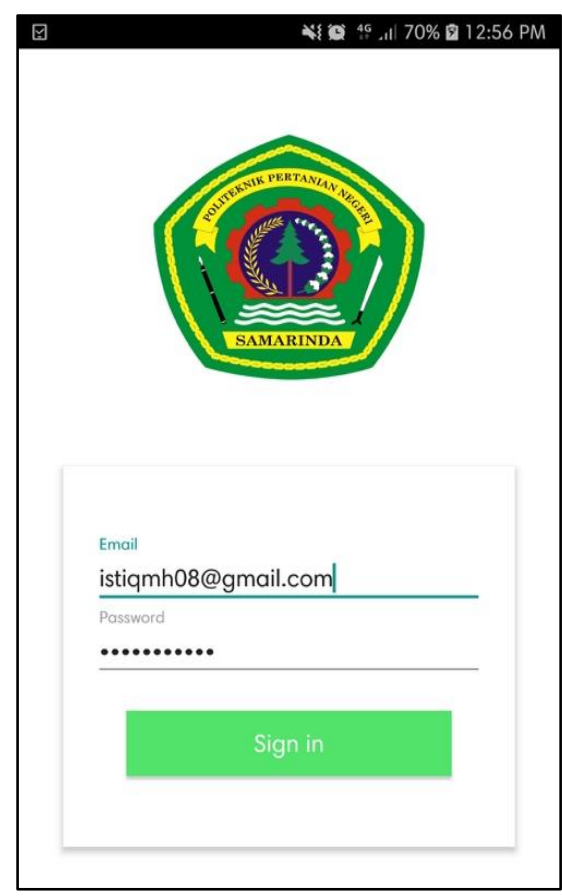

Gambar 8. Tampilan halaman login

\section{HASIL DAN PEMBAHASAN}

\section{A. Hasil Pengembangan Aplikasi}

Berikut adalah hasil implementasi dari perancangan aplikasi evaluasi dosen. User interface ini dibuat untuk memudahkan user dalam menggunakan aplikasi evaluasi dosen. Halaman login adalah halaman awal untuk user atau mahasiswa memasukkan email dan password agar dapat mengakses aplikasi evaluasi dosen. Mahasiswa memasukkan email dan password sebagai otentikasi login lalu klik sign in, kemudian email dan password dirubah menjadi token JWT untuk keamanan akun tersebut. Tampilan pada halaman login dapat dilihat pada Gambar 7.

Halaman welcome atau halaman selamat datang ditampilkan pada saat user berhasil melakukan proses login di aplikasi evaluasi dosen. Pada halaman ini terdapat button untuk memulai proses evaluasi dosen, jika mahasiswa yang akan melakukan evaluasi klik button mulai evaluasi tersebut maka akan ditampilkan halaman yang berisi daftar nama dosen pengampu mata kuliah sesuai dengan semester masingmasing mahasiswa. Berikut tampilannya pada Gambar 8. 


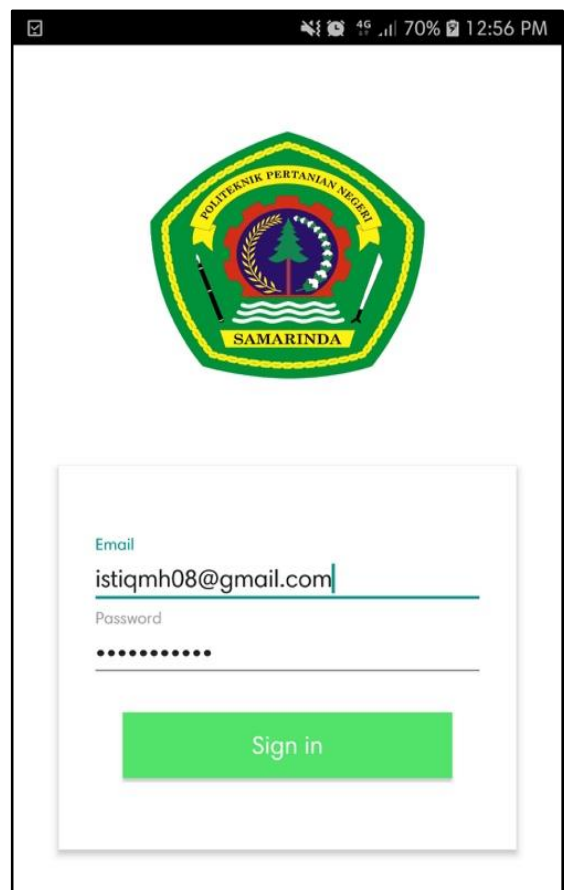

Gambar 9. Tampilan halaman login

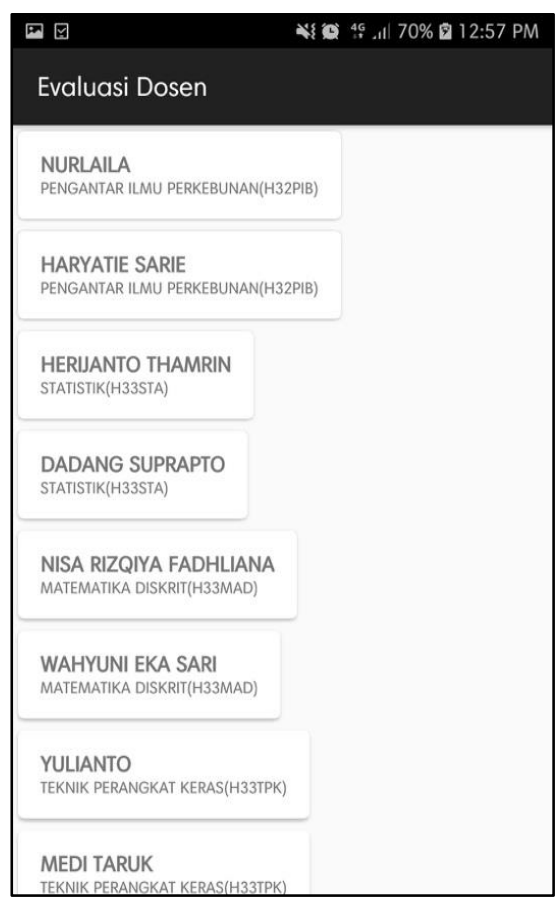

Gambar 10. Tampilan daftar nama dosen mata kuliah

Pada Gambar 9 adalah halaman yang berisi nama-nama para dosen pengampu mata kuliah yang akan dievaluasi oleh mahasiswa sesuai dengan dosen yang mengampu mata kuliah selama satu semester. Setiap nama dosen yang tampil pada halaman ini dapat di klik untuk menampilkan pertanyaanpertanyaan evaluasi dosen. Tampilan halaman pertanyaan evaluasi dosen ini menampilkan seluruh pertanyaan evaluasi yang harus diisi oleh mahasiswa. Pertanyaan-pertanyaan tersebut berdasarkan bagaimana kesiapan mengajar dosen, materi pengajaran, disiplin mengajar, evaluasi mengajar, dan kepribadian dosen.

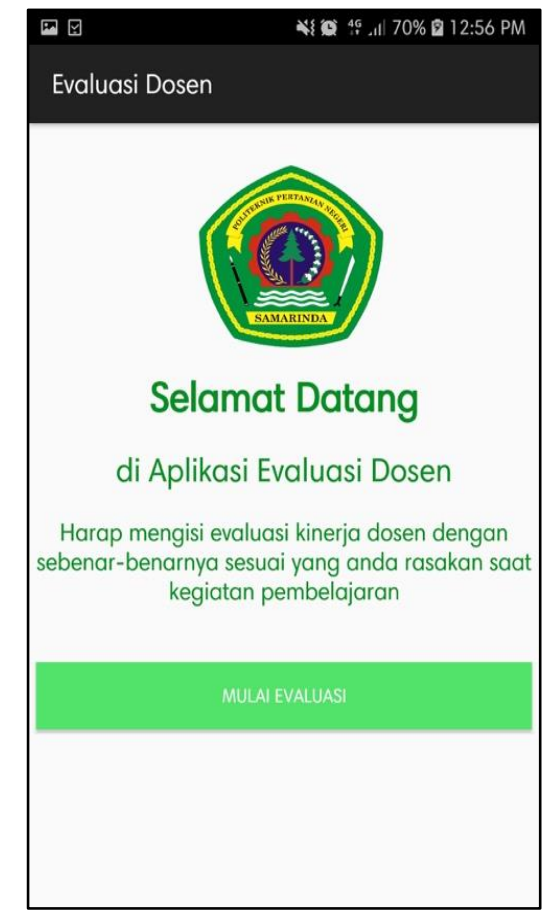

Gambar 11. Tampilan halaman welcome

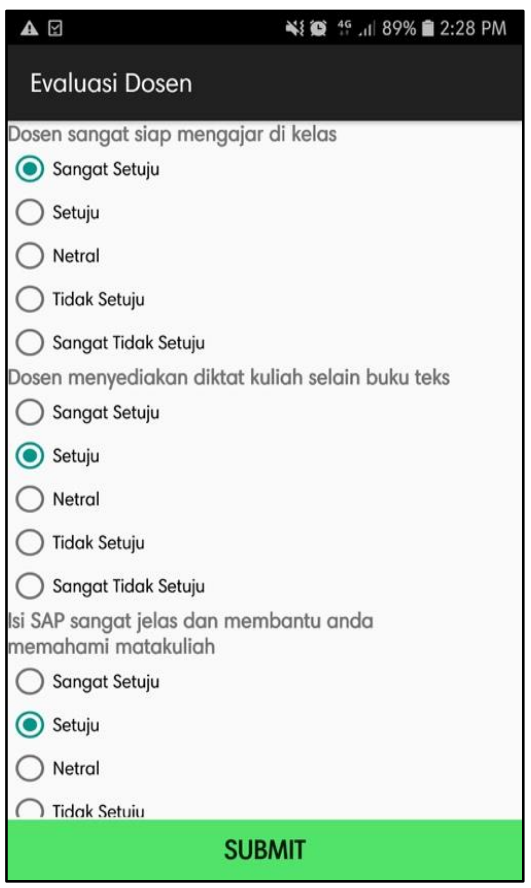

Gambar 12. Tampilan daftar pertanyaan evaluasi dosen

Setiap pertanyaan evaluasi dosen memiliki jawaban dengan lima kriteria berdasarkan skala likert yaitu sangat setuju, setuju, netral, tidak setuju dan sangat tidak setuju. Mahasiswa dapat memilih jawaban sesuai dengan kinerja dosen yang dirasakan selama kegiatan pembelajaran dengan memilih tiap radio button yang disediakan. Pada tampilan pertanyaan ini juga terdapat button submit untuk menyimpan hasil evaluasi dosen dengan klik button submit tersebut seperti Gambar 10. 
Tabel 1. Rencana pengujian aplikasi evaluasi dosen

\begin{tabular}{|c|l|c|}
\hline No. & \multicolumn{1}{|c|}{ Bahan Pengujian } & $\begin{array}{c}\text { Jenis } \\
\text { Pengujian }\end{array}$ \\
\hline 1. & Menampilkan halaman login. & Black box \\
\hline 2. & $\begin{array}{l}\text { Login ke dalam aplikasi evaluasi } \\
\text { dosen. }\end{array}$ & Black box \\
\hline 3. & $\begin{array}{l}\text { Menampilkan halaman welcome } \\
\text { aplikasi evaluasi dosen. }\end{array}$ & Black box \\
\hline 4. & Klik button mulai evaluasi. & Black box \\
\hline 5. & $\begin{array}{l}\text { Menampilkan daftar nama dosen } \\
\text { yang sesuai dengan semester } \\
\text { mahasiswa yang bersangkutan. }\end{array}$ & Black box \\
\hline 6. & $\begin{array}{l}\text { Klik nama dosen untuk tampil } \\
\text { pertanyaan evaluasi dosen. }\end{array}$ & Black box \\
\hline 7. & $\begin{array}{l}\text { Menampilkan halaman daftar } \\
\text { pertanyaan evaluasi dosen. }\end{array}$ & Black box \\
\hline 8. & $\begin{array}{l}\text { Memilih jawaban evaluasi dosen } \\
\text { dengan klik radio button yang } \\
\text { tersedia di tiap jawaban. }\end{array}$ & Black box \\
\hline 9. & $\begin{array}{l}\text { Simpan jawaban atau hasil } \\
\text { evaluasi dosen. }\end{array}$ & Black box \\
\hline 10. & Keluar aplikasi evaluasi dosen. & Black box \\
\hline
\end{tabular}

\section{B. Pengujian Aplikasi}

Pada saat pembuatan sebuah aplikasi tentu perlu dilakukan pengujian aplikasi untuk memeriksa fitur-fitur pada aplikasi yang telah dibuat dapat berjalan dengan baik sesuai dengan fungsinya. Pengujian aplikasi ini dilakukan secara menyeluruh untuk mengetahui apakah aplikasi evaluasi dosen ini dapat menerima, memproses dan memberikan output sesuai dengan perancangan yang direncanakan. Rencana pengujiaPengujian aplikasi evaluasi dosen ini menggunakan metode blackbox dan dilakukan pengujian secara alpha. Metode ini dipilih untuk menemukan kesalahan fungsional dari aplikasi evaluasi dosen. Rencana pengujian aplikasi dapat dilihat pada Tabel 1. Dari rencana pengujian aplikasi diatas yang dilakukan secara alpha dan menggunakan metode black box maka didapatkan hasil yang dpat dilihat pada Tabel 2 .

\section{KESIMPULAN DAN SARAN}

Berdasarkan hasil implementasi dan pengujian aplikasi maka dapat diambil kesimpulan pengembangan web service dapat dipergunakan untuk mengintegrasikan sistem aplikasi evaluasi dosen berbasis android. Sistem yang sudah ada dan dengan keamanan JWT pada web service membantu proses pertukaran data lebih terjamin keamanannya. Dari kesimpulan pengujian aplikasi, saran yang dapat diberikan agar aplikasi yang telah dibuat dapat dikembangkan dengan lebih baik lagi. User interface dapat dibuat lebih menarik lagi untuk digunakan, penambahan fitur-fitur dapat dikembangkan lagi sesuai dengan kebutuhan seperti sms notifikasi atau lainnya. Aplikasi dapat digunakan untuk proses evaluasi dosen khususnya di Politeknik Pertanian Negeri Samarinda.

\section{DAFTAR PUSTAKA}

[1] A. D. Syahputra and F. Marisa, "Penilaian Kinerja Karyawan di Kantor RUPBASAN Kelas II Blitas Dengan Menggunakan Fuzzy Simple Additive
Tabel 2. Hasil pengujian aplikasi evaluasi dosen

\begin{tabular}{|c|l|c|}
\hline No. & \multicolumn{1}{|c|}{ Bahan Pengujian } & Hasil Uji \\
\hline 1. & Menampilkan halaman login. & Berhasil \\
\hline 2. & $\begin{array}{l}\text { Login ke dalam aplikasi evaluasi } \\
\text { dosen. }\end{array}$ & Berhasil \\
\hline 3. & $\begin{array}{l}\text { Menampilkan halaman welcome } \\
\text { aplikasi evaluasi dosen. }\end{array}$ & Berhasil \\
\hline 4. & Klik button mulai evaluasi. & Berhasil \\
\hline 5. & $\begin{array}{l}\text { Menampilkan daftar nama dosen } \\
\text { yang sesuai dengan semester } \\
\text { mahasiswa yang bersangkutan. }\end{array}$ & Berhasil \\
\hline 6. & $\begin{array}{l}\text { Klik nama dosen untuk tampil } \\
\text { pertanyaan evaluasi dosen. }\end{array}$ & Berhasil \\
\hline 7. & $\begin{array}{l}\text { Menampilkan halaman daftar } \\
\text { pertanyaan evaluasi dosen. }\end{array}$ & Berhasil \\
\hline 8. & $\begin{array}{l}\text { Memilih jawaban evaluasi dosen } \\
\text { dengan klik radio button yang } \\
\text { tersedia di tiap jawaban. }\end{array}$ & Berhasil \\
\hline 9. & $\begin{array}{l}\text { Simpan jawaban atau hasil } \\
\text { evaluasi dosen. }\end{array}$ & Berhasil \\
\hline 10. & Keluar aplikasi evaluasi dosen. \\
\hline & & \\
\hline
\end{tabular}

Weighted," JOINTECS (Journal Inf. Technol. Comput. Sci., vol. 4, no. 2, p. 69, 2019.

[2] R. Hidayat, "Performance Appraisal sebagai Alat Pengukuran Kepuasan Kerja Karayawan," Ilman, vol. 3, no. 1, pp. 1-8, 2017.

[3] A. Arvianto, N. U. Handayani, and S. Saptadi, "Pengembangan Indikator Kinerja Utama Untuk Mengukur Keberlanjutan Penelitian Pada Fakultas Teknik Universitas Diponegoro," vol. 2, no. 2, pp. 263-274, 2018.

[4] R. Kusumawati, M. S. Maarif, and S. Nurdiati, "Strategi Peningkatan Kinerja Karyawan Taman Buah Mekarsari," J. Apl. Bisnis dan Manaj., vol. 5, no. 1, pp. 59-70, 2019.

[5] I. Larasati and F. Marisa, "Sistem Aplikasi Penentu Gaji Karyawan pada UD. Mebel DM Menggunakan Metode AHP Berbasis Website," JOINTECS (Journal Inf. Technol. Comput. Sci., vol. 4, no. 1, p. 27, 2019.

[6] P. Agung and F. Marisa, "Analisis Statistik pada Dampak Negatif dari Sosial Media Terhadap Perilaku Manusia," JOINTECS (Journal Inf. Technol. Comput. Sci., vol. 4, no. 1, p. 1, 2019.

[7] C. Andriani and F. Marisa, "Penentuan Penerima Beasiswa Unggul Mulia dan Bidik Misi menggunakan Metode SAW," JOINTECS (Journal Inf. Technol. Comput. Sci., vol. 3, no. 2, pp. 81-84, 2018.

[8] A. Yulianto, S. D. Putra, and R. Haroen, "Sistem Informasi Penunjang Keputusan Penilaian Kinerja Salesman Dengan Metode Simple Additive Weight Berbasis Web Pada PT. Dua Berlian," vol. 3, no. 2, pp. 103-109, 2019.

[9] M. Ishaq, D. Cahyono, and R. N. T. Shanty, "Sistem Pendukung Keputusan Untuk Tender Alat Kesehatan Di Rumah Sakit PKU Muhammadiyah Sekapuk Gresik," JOINTECS (Journal Inf. Technol. Comput. Sci., vol. 4, no. 1, p. 31, 2019.

[10] S. Indah and M. Marini, "Sistem Penilaian Kinerja Karyawan PT. Cahaya Iqra Mandiri Menggunakan 
Metode Analytical Hierarchy Process," vol. 11, no. 10, pp. 110-117, 2019.

[11] D. Sartika and J. Jumadi, "Clustering Penilaian Kinerja Dosen Menggunakan Algoritma K-Means ( Studi Kasus: Universitas Dehasen Bengkulu )," Sainteks, no. 978-602-52720-1-1, pp. 703-709, 2019.

[12] D. R. Pujiati, "Sistem Pendukung Keputusan Evaluasi Kinerja Dosen Berbasis Analytical Hierarchy Process (AHP)," Expert, vol. 2, no. 2, pp. 19-33, 2018.

[13] G. W. Wicaksono and A. Al-rizki, "Peningkatan Kualitas Evaluasi Mutu Akademik Universitas Muhammadiyah Malang melalui Sistem Informasi
Mutu ( SIMUTU )," vol. 1, no. 1, pp. 1-8, 2016.

[14] I. Widaningrum, "EVALUASI KINERJA DOSEN MENGGUNAKAN METODE FUZZY MULTIATTRIBUTE DECISION MAKING ( FMADM ) DENGAN PENGEMBANGAN ( STUDI KASUS : UNIVERSITAS MUHAMMADIYAH PONOROGO )," pp. 61-66, 2013.

[15] I. N. S. Wahyu Wijaya and K. J. Atmaja, "Pengembangan Sistem Evaluasi Kinerja Dosen (EKuesioner) Stmik Stikom Indonesia," JST (Jurnal Sains dan Teknol., vol. 8, no. 1, p. 55, 2019. 
